\title{
Reform of Computer Curricular in University of Political Science -- Example of East China University of Political Science and Law
}

\author{
Meijing Shan ${ }^{1,}$ a * \\ ${ }^{1}$ Department of Information Science and Technology, \\ East China University of Political Science and Law, Shanghai, 201620, China \\ ashanmeijing@ecupl.edu.cn
}

Keywords: Legal Characters, Computer lesson, Computing thinking

\begin{abstract}
At present, the computer curricular in the liberal arts universities is getting more and more attention. To our school - East China University of political science and law(ECUPL) as an example, aiming at cultivating the compound type of law talents, reform the whole computer curricular with legal characters, including the curriculum objectives, content and specific measures for implementation. The aim is to make the legal students think and solve the practical problems in the future work by better logic thinking.
\end{abstract}

\section{Introduction}

In "Opinions on Further Strengthening the basic teaching of computer in Universities”, Ministry of Education figure out the aim of non-professional students to study "computer applications": Training students to have some basic knowledge of computer, understand relevant technologies of hardware and software, possess an ability of solving the problems in their specialties[1].

Nowadays, more and more attention have been paid on teaching computer science at colleges of liberal arts. Almost all of the National Liberal Arts Colleges and universities have set up a basic computer courses. In 2015, computer basic course teaching advisor board under Ministry of Education point out that the basic orientation of computer basic course is "application ", which further emphasizes to cultivate the capability of students to solve problems. Knowledge unit design should correspond to the ability of solving the problem, in this process also cultivate the computational thinking. Many universities open the relevant computer science courses.

The computer basic course mainly teaches computer culture basic, technology basic and application basic. East China normal university is a multidisciplinary university, with the discipline of law being the strongest. Most of the students will be engaged in the work related to law after graduation. At the beginning of the computer basic course, we claim the tight correlation of the computer and the law major. For example, office automation and database basic knowledge; combined with the application of electronic law and electronic government affairs to explain and practice the operation; learn the information science and technology to be able to face the professional application and future employment needs.

\section{In Ecupl, the specialty training goal of law students}

Law students need to master the basic knowledge of law, basic theory and legal professional skills, familiar with the relevant disciplines of knowledge, to be able to combine theory with practice. For law students' training program: relying on owner university, based in Shanghai, radiation whole nation, facing the grassroots, serving the regional economic construction and social development. The students after graduation, will work in national legislation, judicial, administrative, procuratorial organs; will engage in legal teaching, research work at various levels of all kinds of institutions, research institutions; will engage in legal practice in legal service institutions, arbitration institutions; will engage in legal counsel or business management activities, practical ability, and other related disciplines of knowledge[2,3,4]. 
Training mode is solid foundation of knowledge with a strong ability to adapt. Require students to master the basic concepts of various disciplines of law and the basic theory, principles and methods. Master our country's legislative and judicial status and frontier theory, and grasp the development trend of our country legal system construction. To understand the development of legal theory and the formation of legal science theory of new ideas. Master our country's law and related policy of the party and the suitable problem. Have strong legal knowledge and social knowledge analysis, understanding and ability to deal with problems. Have strong ability of writing theory article, all kinds of judicial documents. The student as legal person who is rigorous and rational way of thinking, good oral expression ability. Master law professional skills, and obtain the corresponding professional skills and certificate of qualification.

\section{Existing Computer Teaching Contents and Evaluation}

Our university is based on nationwide, because of local social and economic development imbalance, around the level of freshmen computer operation ability also differ. Individual differences determine that the students differ in interests, learning motivation and others. Most students only want to find a satisfactory job after graduation. A few students continue their studies or apply for civil servants. Therefore, they differ in mindsets, ambition, computer knowledge and skill demand.

\section{Computer Teaching Contents with Legal Character}

For law major students, use computer curriculum as a bridge to lay a good idea of solving problems by computer, foster information literacy, construct reasonable knowledge structure. Guide the law students to consciously use the typical methods in computer science for solving the problems in forward study and research, especially solving the legal matters. Help students to deeply understand computation can extend the human imagination, creativity and understanding. Try to make computer knowledge become a key factor in the basic quality of law students, and lay the foundation for the continuous improvement of the ability to solve the problem in the future.

Based on the above ideas, we carry out the reform on the computer curricular with law character. Set up multilevel practical purposes and corresponding implementation measures.

\section{Theme goal of practical teaching reform}

\section{First : knowledge level-Employment Demand, with law characters.}

In this level, open compulsory course-“Computer Application Base” with law characters. This lesson mainly teach computer culture base, computer technology base and computer application base etc. Add the cross knowledge between computer and the displace of law, such as Information security and crime, cybercrime and law enforcement, network public opinion sentiment, personal privacy protection technology in new network environment. Mainly face the computer basic knowledge needed by the students who will engage in legal, judicial identification and other related work in the future.

\section{Second: ability level-Ability Improvement, with cross knowledge of computer and law.}

In this level, mainly face to cultivate the computer knowledge, technology and application ability of major needed, including Non-computer specialty information core courses and limited optical courses, such as Database application; computer network technology and application; multimedia technology and application; program design foundation, etc. In the teaching process, the content includes computer technology and software application the specialty needed, such as judicial expertise and norms, computer forensics software, network public opinion monitoring technology, improving computer pratical ability.

In nationwide, few university of college open "computational thinking and computational culture" course. The computer teaching team in our university firstly open it as an national science elective course in ECUPL faced to various specialty students. Simultaneously, the course was granted. In the course construction process, we collected and studied the material, and formatted the initial course 
system. We compiled the relevant textbook, and will published by Tsinghua publication. During the construction period, it opened as an elective course in seven universities and gained recognition and praise from students. At the same time, we construct the teaching team. In the successive course construction, we will enrich the content of interdisciplinary applications. We will guide the students to use the computer classic method to solve the problems in their major, through the online teaching resource and Mooc form. Implement the objective of computational thinking.

\section{Third: Quality level-Training computational thinking, cultivating inter-disciplinary person.}

In the level, pay attention to the mutual penetration of information technology and the Social Sciences, prompting students majoring in political science and law apply the computational thinking to the specific study, work and do research. Prepare to solve related to problems of professional field or cross domain. Make computational thinking truly become one factor of the basic quality of he liberal arts students. Provide the foundation to improve the ability of analyzing and resolving problems in the future work, and cultivate interdisciplinary talents with both legal thinking and computational thinking.

Specifically push the reform through the university policies and propaganda of the teachers in class. Encourage the students to attend various science and technology innovation practice activity and information skills contest. The teachers guide students to carry out research work and practice activities, both inside and outside of the class, further deepen students using computer methods for solving the problems in their major. At present, some students majoring in noncomputer science under the guidance of teachers, obtained satisfactory results in national or provincial science and technology innovation contest. Now the students majoring in economic law and criminal investigation carried out the related interdisciplinary research and application in practice. On the other hand, the literal arts undergraduate and graduate students use computational thinking method to do their professional research. It made a very good start.

For example, in e-government and e-commerce applications, the network disputes and crime related to the electronic data are more and more serious. To solve such problem, effectiveness of legal evidence depends on electronic data evidence's discovery, analysis, review and evaluation, etc. Through the study of computer courses, students put forward and designed a set of electronic data evidence evaluation system, both to guarantee the impartiality of the legal process, and to safeguard the electronic data as evidence of appraisal standard and the consistency of the results.

As another example, in the process of the electronic data investigation and forensics involve more and more personal privacy issues. Through the study of computer courses, students can use the method of computer science to explore the way of invasion of privacy in digital forensics, validation of privacy as a civil rights in the process of electronic data forensics to protect the inevitability and feasibility.

\section{Specific implementation measures}

Team members have been engaged in teaching of law and computer technology integration of teaching and scientific research work, according to the common experience of the teaching reform step by step a three goal level in the overall goal is progressive relationship.

\section{For the first object level}

The current main computer foundation course teaching of computer culture basis knowledge, technology and application of three aspects. Our school is as the main body of law and other disciplines and law of the combination of colleges and universities of political science and law. Most students after graduation to work in the related to the law. So at the beginning of the computer application foundation course, the students showed that closely correlation with the computer.

Give characteristics of law to computer courses, especially in terms of application basis, and expand the teaching content. For example, we try to combine office automation software and database with electronic justice and e-government affairs. Let the students gear the information technology needs of major application and the employment demand in the future. 


\section{For the second object level}

After studying the computer basic courses, some of non-computer major students will study the information courses of their own major. The courses involve law, economic, management, public security majors, including "professional statistics and information system ", "management information system", "information management", "electronic commerce foundation", "e-government", "government website construction and management”, "the technology of electronic reconnaissance" and other courses. The involved content mainly include database, multimedia technology and application, etc. Aiming at the first level, through the instance the teacher emphasizes the supplementary role of computer in their majors, extend the students' knowledge. For example, teaching network public opinion and supervision system, introduced the network public opinion monitoring mainly includes the information of the grab, information analysis, mining and match, information review decision points and the final analysis report. Teaching the crime and prevention of mobile terminal in the big data era, mainly introduces the conditions of multi-source heterogeneous data integration, mobile Internet payment security and personal privacy protection against framework, including beforehand prevention, detection, and later forensics omni-directional three-dimensional flow.

Through introducing the computer technology related to their majors, let the students feel the characteristic of Science and Engineering Majors. Require to grasp operating the the mainstream software, improve the computer application ability, and combine with the related laws and regulations.

\section{For the third object layer}

Students are eligible to take the information arbitrary selective courses, mainly include three categories: multimedia software design, program design and application, courses with characteristic of law. The courses with characteristic of law, divided into two classes: one focuses on computer technology, including "information of crime and computer forensics", "electronic evidence", "electronic government affairs", etc. The other focuses on the courses of law, including "Intellectual property protection of computer software", "information law science”, “judicial identification”, etc. The students can parallel learn these two types of courses. In the process of teaching, teachers will add the contents of software security, computer crime and the legal knowledge of Intellectual property protection of computer software, further reflected in computer science and Internet technology to the influence of the law and promote, in order to cultivate students thinking in information security literacy, working in the interdisciplinary professional and comprehensive research.

\section{Special features and innovation}

\section{(1) Special features}

The reform of computer course content with law character, have the following features:

- Systemic: emphasize basic information technology teaching with characteristic of law. Put forward capability enhancement and quality cultivation.

- Pertinence: this topic mainly aims at the students in our university’s curricular reform. We have the background of the discipline of political science and law. The reform reflects the distinctive majors' features.

- Practicality : the knowledge of computer technology have merged from the instances of political science and law. Students learned information knowledge and apply to practice.

- Feasibility: the teaching team members have rich computer teaching experience. So the reform can first pilot and promotion in the whole university. All the teachers in teaching team have national judicial appraiser qualification, and work in the judicial appraisal center which is engaged in computer and video materials judicial appraisal of teaching and scientific research work. Rely on the platform, outstanding students engaged in computer forensics and judicial authentication related internships.

(2) Innovation 
In addition to the above characteristics, also highlighted the following innovation: 1 . Method innovation: gradually-advanced computer teaching curricular reform, cross fusion on teaching law and information technology knowledge, by way of point and line to plane. 2. Content innovation: reform computer teaching content to meet the political science and law major, service of cultivating compound talents, keep the essence of computer teaching and unique legal characteristics.

The current teaching reform mainly based on the characteristics of law and the training of the inter-disciplinary talent. Then through digging out the general law of coures in our universities, set up the topology of curricular which include computer basic course, information support course and legal characteristics of information course. Foothold in the humanities social sciences oriented, Web application oriented, computer teaching curricular reform will spread to the liberal arts colleges.

\section{Conclusions}

(1) Curriculum system: form to teach knowledge - increases ability - cultivate thinking as the main line, gradation and progress method of curriculum system.

(2) Content system: content system: base on the computer basic knowledge with law character, cross law and computer technology knowledge, and aiming at thinking training. Form a complete, Systematic teaching curricular which keeps the computer teaching qualities and possessing characteristics of law.

(3) Practice system: the ECUPL's network security professional teaching staff and laboratory, provide students with computer specialty related practice of teaching content, computer forensics software and hardware operation, establishing demonstration - verification - design - integrated into the practices curriculum system.

\section{Acknowledgements}

This work was supported by Computer teaching reform project in Arts and Humanity Universities of Ministry of Education (No. 2014-A023).

\section{References}

[1] Liberal Art Computer Teaching Advisory Board under the Ministry of Education:

Higher Education Instiutions liberal arts major: College computer Curriculum Requirements. The Six edition. Beijing: Higher education press. (2011).

[2] LI Ji, HUANG Du-pei, WANG Li-mei. Investigation on Major-oriented Fundamental Computer Curricular in the Universities or Colleges of Political Science. Computer Knowledge and Technology. Vol.9, No. 23, 2013.

[3] WANG Li-mei, Li Peng. Research on Computer Teaching Curricular in the Universities or Colleges of Political Science-For example China University of Political Science and Law.

China Legal Education Research, 2006(3): 192-201.

[4] China's institutions of higher learning basic computer education reform project team. In China the computer basic education curriculum system in colleges and universities. Beijing: Tsinghua University Press. (2008). 